\title{
档 \\ FENOMENOLOGIA DA DISTÂNCIA (E DE SUAS CONTRADIÇÕES) EM TEMPOS DE PANDEMIA
}

\begin{abstract}
- ANGELO SERPA
Professor titular de Geografia Humana da Universidade Federal da Bahia, Pesquisador Nível 1B com bolsa de produtividade em pesquisa do Conselho Nacional de Desenvolvimento Científico e Tecnológico. E-mail para contato: angeloserpa@hotmail.com
\end{abstract}

Recebido em:10/07/2020

Aprovado em: 22/01/2021

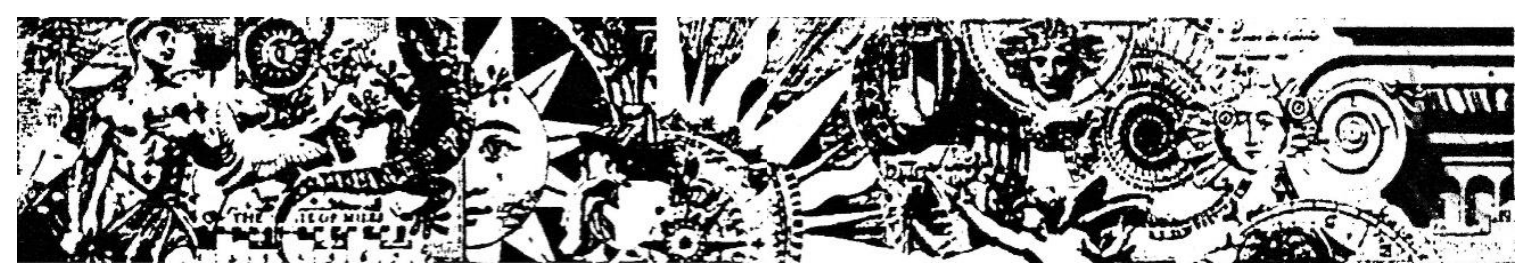

Resumo: Pretende-se com este ensaio problematizar a noção de distância para a Geografia, em um momento de pandemia de COVID 19, que trouxe para a ordem do dia medidas de isolamento e distanciamento social para o controle da disseminação da doença nas cidades do Brasil e do Mundo. Assim, questiona-se, em um primeiro momento, a possibilidade de uma fenomenologia da distância, como uma maneira de problematizar esta noção como categoria e conceito no/para o fazer geográfico e, em um segundo momento, com base em critérios socioculturais, busca-se elaborar uma dialética da distância para o desvelar das contradições advindas da contraposição de seus aspectos materiais e imateriais. Com base em autores como Merleau-Ponty, Heidegger e Bourdieu, conclui-se que a noção de distância apresenta um efetivo potencial organizacional quando a analisamos sob um viés epistemológico e teórico, devendo-se articular diversidade e desigualdade para revelar os paradoxos e contradições engendrados pela distância em diferentes contextos e situações de cunho cultural e social.

Palavras-chave: Distância; Fenomenologia; Dialética; Distanciamento social.

PHENOMENOLOGY OF DISTANCE (AND ITS CONTRADICTIONS) IN PANDEMIC TIMES 


\begin{abstract}
THIS PAPER INTENDS TO DISCUSS THE NOTION OF DISTANCE IN GEOGRAPHY AMID THE COVID-19 PANDEMIC THAT ENTAILED GOVERNMENTAL MEASURES TO CONTROL THE SPREAD OF THIS DISEASE, SUCH AS SOCIAL DISTANCING AND QUARANTINE, IN VARIOUS CITIES IN BRAZIL AND AROUND THE WORLD. FIRSTLY, THE POSSIBILITY OF A PHENOMENOLOGY OF DISTANCE, AS A WAY TO CONCEIVE DISTANCE ITSELF AS A GEOGRAPHICAL CATEGORY AND CONCEPT, IS PUT UNDER SCRUTINY. HENCE, BASED ON SOCIAL AND CULTURAL CRITERIA, WE AIMED TO ELABORATE A DIALECTIC OF DISTANCE TO UNVEIL THE CONTRADICTIONS EMANATED FROM THE OPPOSITION OF ITS MATERIAL AND IMMATERIAL ASPECTS. FINALLY, BASED ON AUTHORS SUCH AS MERLEAU-PONTY, HEIDEGGER, AND BOURDIEU, WE CAME TO THE UNDERSTANDING THAT DISTANCE PRESENTS ORGANIZATIONAL POTENTIAL WHEN ANALYZED UNDER EPISTEMOLOGICAL AND THEORETICAL ANGLES. THEREFORE, TO ACCOMPLISH THAT, DIVERSITY AND INEQUALITY SHOULD BE ARTICULATED BY RESEARCHERS TO REVEAL THE PARADOX AND CONTRADICTIONS ENGENDERED BY DISTANCE IN DIFFERENT CULTURAL AND SOCIAL CONTEXTS AND SITUATIONS.
\end{abstract}

KEYWORDS: DISTANCE; PHENOMENOLOGY; DIALECTICS; SOCIAL DISTANCING.

\title{
FENOMENOLOGÍA DE LA DISTANCIA (Y DE SUS CONTRADICCIONES) EN TIEMPOS DE PANDEMIA
}

RESUMEN: ESTE ENSAYO PRETENDE PROBLEMATIZAR LA NOCIÓN DE DISTANCIA PARA LA GEOGRAFÍA, EN UN MOMENTO DE PANDEMIA POR COVID 19, QUE TRAJO EN AGENDA UNA SERIE DE MEDIDAS DE AISLAMIENTO Y DISTANCIAMIENTO SOCIAL PARA EL CONTROL DE LA PROPAGACIÓN DE LA ENFERMEDAD EN LAS CIUDADES DE BRASIL Y DEL MUNDO. ASÍ, CUESTIONA, EN UN PRIMER MOMENTO, LA POSIBILIDAD DE UNA FENOMENOLOGÍA DE LA DISTANCIA, COMO FORMA DE PROBLEMATIZAR ESTA NOCIÓN COMO CATEGORÍA Y CONCEPTO EN/PARA EL QUEHACER GEOGRÁFICO Y, EN UN SEGUNDO MOMENTO, A PARTIR DE CRITERIOS SOCIOCULTURALES, SE BUSCA DESARROLLAR UNA DIALÉCTICA DE LA DISTANCIA PARA DESVELAR LAS CONTRADICCIONES QUE SURGEN DE LA OPOSICIÓN DE SUS ASPECTOS MATERIALES E INMATERIALES. CON BASE EN AUTORES COMO MERLEAU-PONTY, HEIDEGGER Y BOURDIEU, SE CONCLUYE QUE LA NOCIÓN DE DISTANCIA PRESENTA UN POTENCIAL ORGANIZACIONAL EFECTIVO CUANDO LA ANALIZAMOS BAJO UNA PERSPECTIVA EPISTEMOLÓGICA Y TEÓRICA, DEBIÉNDOSE ARTICULAR DIVERSIDAD Y DESIGUALDAD PARA REVELAR LAS PARADOJAS Y CONTRADICCIONES ENGENDRADAS POR LA DISTANCIA EN DIFERENTES CONTEXTOS Y SITUACIONES DE CARÁCTER CULTURAL Y SOCIAL.

PALABRAS CLAVE: DISTANCIA; FENOMENOLOGÍA; DIALÉCTICA; DISTANCIAMIENTO SOCIAL.

\section{Introdução}

Esse ensaio resulta da convergência de dois momentos: o convite para escrever e publicar no número comemorativo de 25 anos do periódico Espaço e Cultura, editado pelo NEPEC-UERJ, e a conjuntura de pandemia de COVID 19 em $2020^{1}$, que trouxe

\footnotetext{
${ }^{1}$ Esse texto foi finalizado em novembro de 2020, quando a pandemia dava sinais de repique no Brasil e medidas de restrição estavam sendo retomadas em alguns estados e cidades do país. 
para a ordem do dia medidas de isolamento e distanciamento social nas cidades do Brasil e do Mundo.

Uma questão inicial, que norteia como pano de fundo esta reflexão, passa pelo questionamento se em determinados contextos socioculturais manter-se distante e evitar a proximidade com outras pessoas seria algo mais fácil ou difícil a depender da maneira como encaramos o contato com o outro nos espaços domésticos ou de uso coletivo.

Sem a intenção de reforçar estigmas ou estereótipos sociais e espaciais, lembramos que o senso comum em geral diz que em determinados países e culturas a sociabilidade mobiliza mais afetos e mais proximidade que em outros países/culturas, que, por exemplo, o toque e o abraço se expressam de modo diferente e plural entre os seres humanos ao redor do mundo, a depender da maneira como são socializados.

De qualquer modo, é mister reconhecer que a distância, como uma categoria geográfica, não pode ser vista apenas como uma medida objetiva, que possa ser reduzida a uma métrica una e universal. Estamos aqui diante de uma discussão que de alguma forma também posiciona de um modo particular a Geografia frente às demais ciências, sociais e naturais.

Nesse contexto, parece pertinente lembrar, com Lévy e Lussault (2003), que a noção de distância está no centro de toda concepção de espaço e que "uma das fraquezas estruturais da Geografia foi, durante muito tempo, a de não ter refletido teoricamente sobre a distância, o que a impediu de tirar partido das filosofias espaciais e dos conceitos de distância de outras disciplinas" (LÉVY, LUSSAULT, 2003, p. 267, tradução nossa). Levy e Lussault (2003) vão sublinhar o fato de que a distância não se separa das realidades que ela configura, já que no domínio do social “toda distância é social”: “Além disso, as distâncias imateriais, simbólicas, imaginárias são tão concretas quanto as distâncias materiais” (LÉVY, LUSSAULT, 2003, p. 269, tradução nossa). Porém,

apesar do caráter central da distância para toda ciência social do espaço, os modelos espaciais baseados em medidas de distância apresentaram na maior parte do tempo o inconveniente de se contentar com uma medida universal, porque convencional, independente, por um lado, dos objetos que essa distância ligava, e, por outro lado, dos contextos espaciais nos quais esta relação estava inscrita (LEVVY, LUSSAULT, 2003, p. 269, tradução nossa).

Assim, questiona-se com esse ensaio, em um primeiro momento, a possibilidade de uma fenomenologia da distância, como uma maneira de problematizar esta categoria/este conceito no/para o fazer geográfico e, em um segundo momento, com base em critérios socioculturais, busca-se elaborar uma dialética da distância para o 
desvelar das contradições advindas da contraposição de seus aspectos materiais e imateriais.

\title{
Sobre a possibilidade de uma fenomenologia da distância
}

A possibilidade de uma fenomenologia da distância passa necessariamente pela dimensão da percepção nos moldes como Merleau-Ponty vai discutir, por exemplo, a relação entre grandeza aparente e distância, ao se questionar se um homem a duzentos passos não seria menor que um homem a cinco passos. No entanto, o autor chama atenção para o fato de que este homem só se torna menor se meço sua grandeza aparente e o isolo do contexto percebido:

\begin{abstract}
De outra maneira, ele não é nem menor, aliás nem igual em grandeza: ele está aquém do igual e do desigual, ele é o mesmo homem visto de mais longe. Pode-se dizer apenas que o homem a duzentos passos é uma figura muito menos articulada, que ele oferece ao meu olhar pontos de apoio menos numerosos e menos precisos, que ele está menos estritamente engrenado no meu poder explorador. Pode-se dizer ainda que ele ocupa menos completamente o meu campo visual, sob a condição de nos lembrarmos que o campo visual não é ele mesmo uma área mensurável (MERLEAU-PONTY, 2006, p. 351352 , grifos no original).
\end{abstract}

Desse modo, nosso campo visual não é pré-definido para conter mais ou menos coisas, porque isso vai depender justamente se vejo essas coisas de mais longe ou de mais perto. Ou seja, não se define a grandeza aparente separada da distância, porque ambas estão implicadas uma na outra: "Convergência, grandeza aparente e distância se lêem umas nas outras, se simbolizam ou se significam naturalmente umas às outras, são os elementos abstratos de uma situação e, nesta, são sinônimas umas das outras" (MERLEAU-PONTY, 2006, p. 352).

Ressalte-se que o sujeito da percepção não relaciona objetivamente convergência, grandeza aparente e distância, mas, ao contrário, porque não as dispõe de modo apartado não necessita expressamente ligá-las/relacioná-las. Isso quer dizer que nós "temos” este objeto que se distancia de nós: "não deixamos de possuí-lo e de ter poder sobre ele, e a distância crescente não é, como a largura parece sê-lo, uma exterioridade que cresce" (MERLEAU-PONTY, 2006, p. 352). E isso quer dizer, em última instância, que, no terreno da percepção, a distância é algo que diferencia uma "apreensão esboçada" de uma “apreensão completa”, esta última que é também o mesmo que proximidade. 
Seguindo o raciocínio de Merleau-Ponty, pode-se afirmar que a distância se define pela "situação do objeto" em relação à potência de sua apreensão (MERLEAUPONTY, 2006, p. 353). É a percepção que nos proporciona um “campo de presença” em sentido mais amplo, "que se estende segundo duas dimensões: a dimensão aqui-ali e a dimensão passado-presente-futuro", a segunda permitindo a compreensão da primeira, já que nós possuímos ou temos "o objeto distante sem posição explícita da perspectiva espacial (grandeza e forma aparentes)", assim como ainda temos em mãos "o passado próximo sem nenhuma deformação, sem ‘recordação’ interposta” (MERLEAU-PONTY, 2006, p. 357-8).

Para Merleau-Ponty, nós nunca compreenderemos a percepção da distância se partirmos "de conteúdos dados em uma espécie de equidistância, projeção plana do mundo como as recordações são uma projeção do passado no presente" (MERLEAUPONTY, 2006, p. 358). Do mesmo modo que só se pode entender a memória como uma "posse direta do passado, sem conteúdos interpostos”, só se compreende a percepção da distância "como um ser no longínquo" que nos "alcança ali onde ele aparece" (MERLEAUPONTY, 2006, p. 358, grifos no original).

O ser no longínquo nos alcança porque ser é ser-no-espaço e, "ao atribuirmos espacialidade à presença, temos evidentemente de conceber este 'ser-no-espaço', a partir de seu modo de ser" e esta espacialidade é uma espacialidade do ser-em, que apresenta, segundo Heidegger, os caracteres do dis-tanciamento e do direcionamento (HEIDEGGER, 2012, p. 158, grifo no original). Mas, aqui, distanciamento é algo a mais do que distância como proximidade ou intervalo. Em Heidegger, distanciamento apresenta significado ativo e transitivo:

Indica uma constituição de ser da presença em virtude da qual o distanciar de alguma coisa, no sentido de afastar, é apenas um modo determinado e fático. Distanciar diz fazer desaparecer o distante, isto é, a distância de alguma coisa diz proximidade. Em sua essência, a presença é em dis-tanciando. Como o ente que é, sempre faz com que os entes venham à proximidade. $\mathrm{O}$ dis-tanciamento descobre a distância. Assim como o intervalo, a distância é uma determinação categorial dos entes destituídos do modo de ser da presença. Distanciamento, ao contrário, deve ser mantido como existencial (HEIDEGGER, 2012, p. 158).

Vemos que, ao distinguir a distância do distanciamento e atribuir a este último o caráter de existencial, Heidegger busca diferenciar o ser da presença dos demais entes intramundanos, radicalizando no propósito de construção de uma ontologia espacial para revelar, na presença, uma tendência essencial de proximidade (HEIDEGGER, 2012, p. 159), que se revela cotidianamente através da circunvisão e da ocupação: 
Embora não necessariamente, subsiste no distanciamento uma avaliação explícita da distância em que um manual se acha com relação à presença. A distância jamais é apreendida de antemão como intervalo. A avaliação da distância sempre se faz relativamente a dis-tanciamentos em que a presença cotidiana se mantém. Por mais imprecisos e oscilantes que sejam os seus cálculos, tais avaliações possuem uma determinação própria e compreensível para todos no modo de ser cotidiano da presença. Assim dizemos - até lá é um passeio, é um pulo, são 'dois passos'. Essas medidas exprimem que elas não apenas não querem 'medir' como também indicam que as distâncias avaliadas pertencem a um ente com que lidamos numa circunvisão e ocupação (HEIDEGGER, 2012, p. 159, grifo no original).

Ao se deslocar, a presença "não atravessa um trecho do espaço como uma coisa corpórea simplesmente dada", "ela não devora quilômetros", porque dis-tanciamento e aproximação devem ser interpretados sempre como modos de ocupação com o que está distante e o que está próximo (HEIDEGGER, 2012, p. 160); porque, por ser essencialmente espacial, para a presença, "o lidar com as coisas sempre se mantém num 'mundo circundante', cada vez determinado por um certo espaço de jogo” (HEIDEGGER, 2012, p. 160). Assim, "ver e ouvir são sentidos da distância, não devido ao seu alcance, mas porque, distanciando-se, a presença neles se mantém de forma predominante" (HEIDEGGER, 2012, p. 161).

A ideia de ocupação é central para se compreender o distanciamento como existencial, já que a presença sempre “ocupa um lugar”, um ocupar que, segundo Heidegger, "deve ser concebido como distanciar o manual do mundo circundante dentro de uma região previamente descoberta numa circunvisão” (HEIDEGGER, 2012, p. 161). Sob essa ótica, "a presença compreende o aqui a partir de um lá do mundo circundante" (HEIDEGGER, 2012, p. 161), o aqui se constituindo como "o estar junto de um ser que produz dis-tância” (HEIDEGGER, 2012, p. 162). É interessante perceber como Heidegger coloca ênfase no dis-tanciar como característica inerente ao ser-no-mundo, enfatizando que a presença "nunca está aqui, mas sempre lá” (HEIDEGGER, 2012, p. 162).

Assim, "como ser-no-mundo, a presença se mantém essencialmente num distanciar. (...) A presença não cruza de forma alguma o seu dis-tanciamento e isso a tal ponto que o leva consigo constantemente, pois a presença é essencialmente dis-tanciamento, ou seja, é espacial' (HEIDEGGER, 2012, p. 162, grifos no original). Estabelece-se, portanto, uma dialética entre aproximar e dis-tanciar, aproximar significando "na periferia do que está imediatamente à mão numa circunvisão" (HEIDEGGER, 2012, p. 161). A aproximação, como o dis-tanciamento se norteiam, pois, pelo ser-no-mundo da 
ocupação. E porque possui também o caráter do direcionamento, a "ocupação exercida na circunvisão é um dis-tanciamento direcional” (HEIDEGGER, 2012, p. 162).

\section{As contradições socioespaciais engendradas pela distância}

A noção de distância apresenta um efetivo potencial organizacional quando a analisamos sob um viés epistemológico e teórico: "Para as sociedades, o problema do espaço pode ser visto como a gestão das contradições engendradas pela distância, que impedem a interação” (LÉVY; LUSSAULT, 2003, p. 269, tradução nossa). Assim, o sentido fenomenológico/ontológico da ideia de "ocupação" pode ser ampliado para abarcar um conteúdo social para a presença, para o ser-no-mundo, acionando as ideias de enclave, ubiquidade, copresença, transporte (percursos materiais para estabelecer uma ligação entre duas realidades distantes), telecomunicações (transferências de conteúdo imaterial) etc.

"Colocar à distância” enquanto ação/ocupação apresenta a um só tempo uma dimensão social e uma dimensão espacial. Levy e Lussault (2003), baseados em Norbert Elias, lembram que o distanciamento "manifesta a capacidade de um ator para controlar seus afetos, suas emoções e seus sentimentos em relação aos acontecimentos que o rodeiam” (LÉVY; LUSSAULT, 2003, p. 271, tradução nossa). No entanto, o distanciamento e o seu oposto - o engajamento (a proximidade) - são "tipos" ideais porque os indivíduos transitam mais comumente entre esses dois extremos de acordo com o tipo de sociedades (o que inclui sua posição/condição na estrutura social, ou seja, sua classe social) às quais pertencem e segundo as situações cotidianas vividas por eles.

Para Bourdieu, o "distanciamento" é o princípio da experiência burguesa do mundo, expressa de modo evidente em uma "disposição estética" desembaraçada da urgência, "assim como na prática de atividades que têm sua finalidade em si mesmas, por exemplo, os exercícios escolares ou a contemplação de obras de arte” (BOURDIEU, 2007, p. 55). São os atos "distanciados", ou seja, "desinteressados" e "gratuitos", que produzem sua raridade distintiva na estrutura social, porque "o poder econômico é, antes de tudo, o poder de colocar a necessidade econômica à distância. (...) O consumo material ou simbólico da obra de arte constitui uma das manifestações supremas da abastança no sentido da condição" e da posição na estrutura social (BOURDIEU, 2007, p. 55). 
Assim, quanto maior a distância objetiva da necessidade, mais os estilos de vida aproximam-se de um processo de "estilização da vida”, "expediente sistemático que orienta e organiza as mais diversas práticas” (BOURDIEU, 2007, p. 56). Portanto,

a disposição estética é a dimensão de uma relação distante e segura com o mundo e com os outros que pressupõe a segurança e a distância objetivas; a manifestação do sistema de disposições que produzem os condicionamentos sociais associados a uma classe particular de condições de existência quando eles assumem a forma paradoxal da maior liberdade concebível, em determinado momento, em relação às restrições da necessidade econômica (BOURDIEU, 2007, p. 56).

A distinção e a distância estão na base da definição do conceito de habitus. Para Bourdieu (2007), o habitus é ao mesmo tempo um princípio gerador de práticas sociais e um sistema de classificação dessas práticas. É da relação dessas duas características que definem o habitus - capacidade de produzir práticas e objetos passíveis de classificação e capacidade de apreciar e diferenciar essas práticas e objetos (gosto) - que se origina o mundo social das representações, o espaço dos estilos de vida.

O habitus é estrutura estruturante, que organiza as práticas e a percepção das práticas, mas também estrutura estruturada, produto da divisão em classes sociais. Cada posição/condição é definida por suas propriedades intrínsecas, mas também por suas propriedades relacionais em um sistema de diferenças, de posições diferenciais, por tudo aquilo que ela não é, tudo que a distingue e que a opõe a outras posições/ condições.

O princípio gerador das diferenças no âmbito do consumo é a oposição entre gostos de luxo (ou de liberdade) e os gostos de necessidade. Os primeiros são próprios dos indivíduos que são produto de condições materiais de existência definidas pela distância da necessidade, pela liberdade, pelas facilidades asseguradas pela possessão de um capital; os segundos exprimem as necessidades, das quais eles são produto.

Percebe-se que, em Bourdieu, a distância adquire uma conotação explicitamente hierárquica que dispõe indivíduos/sujeitos (grupos e classes) de acordo com sua posição/condição na estrutura social, estabelecendo-se distâncias que têm também o caráter da desigualdade, da segregação e da fragmentação e que se manifestam igualmente em termos espaciais nos processos de criação/produção do espaço, determinando uma acessibilidade em termos espaciais e sociais que não é somente física, mas apresenta, sobretudo, um caráter simbólico e imaterial (SERPA, 2007).

"Os sujeitos sociais distinguem-se pelas distinções que eles operam entre o belo e o feio, o distinto e o vulgar; por seu intermédio, exprime-se ou traduz-se a posição desses sujeitos nas classificações objetivas” (BOURDIEU, 2007, p. 13). O senso de ESPAÇO E CULTURA, UERJ, RJ, JAN./JUN. DE 2021, N. 49, P. 143-155. http://www.e-publicacoes.uerj.br/index.php/espacoecultura/ 
distinção que baseia o habitus de classe une e separa, aproxima e distancia, unindo "todos aqueles que são o produto de condições semelhantes, mas distinguindo-os de todos os outros" (BOURDIEU, 2007, p. 56). Estamos aqui diante da distância e do distanciamento como desigualdade social e espacial.

E é claro que, em uma formação socioespacial, como a brasileira, as desigualdades (de cunho social, mas também regional) vão condicionar uma maior ou menor adesão ao distanciamento social como estratégia de enfrentamento da COVID-19, porque a proximidade da necessidade, nos termos de Bourdieu, aqui sinteticamente apresentados, impede/impediu o distanciamento social por questões de sobrevivência para uma imensa parcela da população brasileira. Isso significa que a pandemia colocou mais uma vez em evidência as imensas desigualdades existentes no país, de resto mais problematizada nos últimos anos como na pesquisa realizada pela ONG britânica OXFAM Brasil, cujos resultados foram divulgados em 2017 através do relatório "A distância que nos une Um retrato das desigualdades brasileiras". Dados estarrecedores dessa pesquisa revelaram que as desigualdades ainda se manifestam de modo gritante no país.

A carga tributária que incide sobre os mais pobres, por exemplo, é superior àquela que cabe aos mais ricos: os 10\% mais pobres gastam $32 \%$ de sua renda em impostos, a maior parte pelo consumo de bens e serviços, enquanto que os mais ricos gastam apenas $21 \%$. Ou seja, a carga tributária contribui para o aumento do abismo social entre ricos e pobres, já que o país cobra mais impostos das pessoas físicas que das pessoas jurídicas. Acrescente-se a isso o fato de os impostos sobre a propriedade serem mais robustos para automóveis que para imóveis e heranças e pode-se chegar à conclusão que uma reforma tributária poderia atenuar de modo mais eficiente as desigualdades reinantes no Brasil do que programas sociais como o Bolsa Família, uma conquista dos mais pobres nas últimas décadas.

Os dados da Receita Federal de 2016 são detalhados pela Oxfam Brasil, mostrando que "as pessoas com rendimentos mensais superiores a 80 salários mínimos $(\mathrm{R} \$ 63.040,00)$ têm isenção média de $66 \%$ de impostos, podendo chegar a $70 \%$ para rendimentos superiores a 320 salários mínimos mensais ( $\mathrm{R} \$ 252.160,00$ )” (OXFAM BRASIL, 2017, p. 46). Considerando-se as faixas de 3 a 20 salários mínimos, compatíveis com os segmentos médios de renda, a isenção é de $17 \%$, caindo para $9 \%$ na faixa de 1 a 3 salários mínimos mensais. "Em resumo, as menores rendas e a classe média pagam proporcionalmente muito mais imposto de renda que os super-ricos" (OXFAM BRASIL, 2017 , p. 46). 
Nesse contexto, habitar/ocupar são condicionados por e condicionantes de distanciamentos que nem sempre podem ser encarados como "escolhas" para todas as classes sociais, visto que, no caso da estratégia de distanciamento social para combater a evolução da pandemia no país (e no mundo), é evidente que as condições objetivas desse habitar/ocupar (tamanho dos domicílios, número de cômodos das residências, número de moradores por residência, condições de saneamento etc.) são aspectos determinantes para a maior ou menor adesão ao distanciamento. Isso, sem falar no acesso ao mercado de trabalho e ao emprego, nos tipos de ocupação socioprofissional, bem como nas condições extremamente desiguais de mobilidade nas cidades/regiões do país para as diferentes classes, entre outros aspectos.

Mas será que podemos pensar nessa questão para além das desigualdades sociais, ressaltando o caráter cultural das diferentes formações socioespaciais, como o faz Bourdieu em relação à estrutura social, a partir da conceituação de habitus e de sua operacionalização em termos de gostos e estilos de vida? Ou seja, a depender de diferenças regionais e nacionais seria possível estabelecer que em determinados contextos e países o distanciamento seria mais facilmente "praticado" e, portanto, "culturalmente" mais entranhado nas práticas sociais e espaciais, que em outros países/contextos? Essa é uma questão interessante - mas de difícil resposta - porque oportuniza a discussão sobre determinismos culturais e espaciais, "relativizando" as desigualdades expressas em sociedades de classe.

De acordo com uma reportagem da BBC News Brasil, "sociedades norte e latinoamericanas são mais abertas, enquanto sociedades asiáticas e norte-africanas são mais fechadas" (SAYURI, 2020, s/p). A matéria se baseia em um estudo internacional, "The Relational Mobility", realizado por 27 pesquisadores de 19 universidades e publicado na revista científica da National Academy of Sciences, dos Estados Unidos, em $2018^{2}$ (THOMSON et al., 2018). Uma ideia-chave nesse contexto é a de Mobilidade relacional (relational mobility) que mobiliza uma área de estudos e pesquisas interdisciplinares (da biologia à sociologia), que se debruça sobre tendências de comportamento das sociedades dos diferentes países para relacionamentos amorosos e amizades, por exemplo:

É uma 'variável socioecológica', que representa o grau de liberdade e de oportunidade que as pessoas têm para escolher, iniciar e romper seus relacionamentos interpessoais, a partir de suas preferências pessoais. Em termos simples, uma sociedade de alta mobilidade relacional é mais aberta, passional e sociável, com relações sociais mais

\footnotetext{
2 "Foram tabulados mais de 16 mil questionários de 12 perguntas, em 23 idiomas, que incluíram pontos como: no seu círculo social, é comum ver pessoas conversando com alguém que nunca viu antes? É fácil conhecer pessoas novas? É possível escolher com quem interagir no dia a dia?” (SAYURY, 2020, s/p). ESPAÇO E CULTURA, UERJ, RJ, JAN./JUN. DE 2021, N. 49, P. 143-155. http://www.e-publicacoes.uerj.br/index.php/espacoecultura/
} 
fluidas e íntimas; uma sociedade de baixa mobilidade relacional, por sua vez, é mais fria, fechada e reservada, de relações mais engessadas e distantes (SAYURI, 2020, s/p).

De acordo com isso, países com sociedades mais "abertas", como o Brasil, vão provavelmente lidar com a condição de distanciamento (e isolamento) social sob mais tensão e estresse, do que países com sociedades mais "fechadas", como o Japão. O psicólogo social Junko Yamada, do Departamento de Ciência Comportamental da Universidade de Hokkaido, entrevistado na reportagem da BBC NEWS, lembra que "interações físicas como beijos, abraços e apertos de mão são importantes para formar e fortalecer relacionamentos. A disseminação do vírus restringe esses comportamentos" (SAYURI, 2020, s/p).

Outro pesquisador citado na reportagem da BBC, o único brasileiro entre os autores do referido estudo, o psicólogo pernambucano Taciano Milfont, à época da realização da entrevista diretor do Centre for Applied Cross-Cultural Research da Universidade Victoria de Wellington ${ }^{3}$, na Nova Zelândia, lembra que os seres humanos são uma espécie social, mas que ficar isolado e distante em um país "fechado" como o Japão ou em um país "aberto" como o Brasil são experiências bem distintas. Ele ressalta que "todo mundo é impactado, mas de maneiras diferentes. O Brasil é um território imenso, onde as relações tendem a ser muito mais próximas, conforme indicam os dados. Nós, brasileiros, temos o costume de abraçar, dar as mãos, tocar nos outros e ficar sem isso pode ser difícil" (SAYURI, 2020, s/p).

Vemos que as pesquisas no campo da mobilidade relacional acrescentam novas dimensões para a análise do distanciamento social como estratégia de enfrentamento da COVID-19, contrapondo aspectos de diversidade regional/territorial/nacional às questões relacionadas às desigualdades socioespaciais como discutido anteriormente. Como já abordei em outras oportunidades (SERPA, 2018), ao tratar de diversidade social em nossas pesquisas manejamos conceitos e categorias distintos do que quando assumimos uma abordagem focada na desigualdade social, partindo também de dados e recortes bem diferenciados. Se a diversidade é o foco, nos debruçamos sobre questões e processos de cunho identitário, de afirmação de identidades (sejam elas identidades regionais/territoriais/nacionais sejam as identidades de gênero e raça/etnicidade).

Explicita-se aqui o dilema entre conjuntura e estrutura, entre o particular e o geral. Se partirmos das estruturas, do geral, as classes e suas frações vão nortear uma análise socioespacial que pode subsumir outras categorias importantes como gênero,

\footnotetext{
${ }^{3}$ Atualmente trabalha na Universidade de Waikato. 
raça/etnicidade, identidades nacionais/territoriais/regionais etc., base para explicitação de processos identitários que se revelam na maior parte das vezes de modo conjuntural e em escalas mais concretas. Observe-se que o contrário também pode ocorrer, pois uma análise conjuntural, baseada nas subjetividades e nos coletivos "identitários", como também vem ocorrendo em Geografia, pode da mesma maneira desconsiderar aspectos importantes da estrutura social e as questões de classe envolvidas (SERPA, 2018).

Voltemos aos dados da Oxfam Brasil (2017), já citados nesse ensaio, relativos às desigualdades de gênero e raça/etnicidade. Ter maior escolaridade para a população negra não significa alcançar os mesmos rendimentos que entre os brancos. Com ensino médio completo, os negros recebem $76 \%$ do rendimento médio de brancos na mesma faixa educacional; e, com ensino superior completo, $75 \%$ do rendimento médio da população branca. Entre as mulheres, que em geral têm escolaridade superior $(8,4$ anos de estudo) àquela dos homens ( 8 anos de estudos), a diferença salarial entre os gêneros é ainda mais acentuada nas mesmas faixas educacionais. Com ensino médio completo, as mulheres ganham 66\% do que os homens; e, com ensino superior completo, apenas 63\% do que recebem os homens. A mesma situação se repete com negros e mulheres que exercem as mesmas profissões ${ }^{4}$.

Percebe-se que, mesmo com uma análise focada nas desigualdades sociais, a partir do recorte específico da formação socioespacial brasileira, as diferenças de gênero e raça/etnicidade acabam por potencializar as hierarquias presentes na estrutura social (SERPA, 2018). Ou seja, diferença e desigualdade se influenciam e fortalecem mutuamente, o que exige uma articulação constante de categorias analíticas com diferentes características/qualidades se se deseja explicitar as questões relativas ao distanciamento social diante da pandemia de COVID-19 em diferentes contextos e situações socioculturais.

\footnotetext{
4 "Negros e mulheres estão concentrados em carreiras com menor remuneração, e tendem a ganhar menos que brancos e homens mesmo nestas carreiras. Um médico negro ganha, em média, $88 \%$ do que ganha um médico branco. No caso de uma formação de menor remuneração com grande participação de negros (...) ainda assim a proporção do rendimento por eles recebido é de $83 \%$ em relação ao rendimento médio dos brancos de mesma formação e profissão. No caso de mulheres, as diferenças são mais gritantes. Médicas ganham, em média, 64\% dos rendimentos de homens médicos, e mulheres economistas ganham $61 \%$ do que ganham, em média, seus colegas homens. Em formações de menor remuneração com grande participação feminina, como letras, mulheres ganham em média 80\% do que ganham os homens” (OXFAM BRASIL, 2017, p. 64). 


\section{À guisa de conclusão: A distância que nos separa é a mesma que nos une}

Chernobyl, Hiroshima, Goiânia, Mariana, Brumadinho, Santo Amaro: O que essas cidades têm em comum? Catástrofes humanas sem precedentes, que deixaram marcas profundas na paisagem e repercutem ainda hoje na vida de seus habitantes. Marcas nem sempre visíveis, pois, anos depois das ocorrências, corpos doentes invisibilizados em hospitais não fazem propriamente parte da paisagem para quem não quer ver os males invisíveis que nos assolam enquanto humanidade e civilização.

"A distância é nossa melhor proteção", diz um dos personagens do espetáculo "Mal Invisível”, em cartaz durante o mês de outubro de 2019, no Teatro Vila Velha, em Salvador-Bahia ${ }^{5}$. Encerrado em uma espécie de exposição científico-artística com outras vítimas de degradações a todos impostas pelo desapreço à Natureza e ao planeta, o ser sem nome instiga o público a refletir sobre a morte e o amor. Na peça, a distância é uma espécie de personagem “oculto”, metáfora para falar da segregação e do isolamento dos indesejáveis da sociedade. O público é colocado em situação confortável de observador distanciado dessas vítimas, humanos como nós, mas distantes o suficiente para não "contaminar" a plateia dos terríveis males ali expostos.

A distância entre público e personagens, explicitada na configuração espacial do espetáculo - com dramaturgia do diretor e ator Marcelo Sousa Brito, inspirada na obra La supplication, da autora bielorrussa Svetlana Alexievitch - é, no entanto, quebrada pela lembrança de nossas próprias catástrofes, mostrando que Chernobyl, Santo Amaro e Goiânia possuem algo em comum. E o isolamento torna invisíveis também nossas tragédias sociais cotidianas, as separações, o racismo ambiental e institucional, a imensa desigualdade ocultada pelo manto do "progresso".

Para se aproximar dessa realidade, o elenco dividiu seus ensaios e processo criativo com moradores da Comunidade do Solar do Unhão, em Salvador, porque, para Sousa Brito, "não se pode falar do cotidiano, da vida real, preso em salas de ensaio”. Foi necessário que os atores vivessem na pele "as dores e delícias das personagens", para “ouvir o grito dos invisibilizados pela sociedade", e levar à comunidade "o clamor de artistas-personagens que querem problematizar nossa estadia na Terra e o que será das civilizações futuras”.

\footnotetext{
${ }^{5}$ Mais detalhes sobre a peça em: https://www.youtube.com/watch? $\mathrm{v}=\mathrm{nvOnX}$ s4b9Q Acesso em 26/11/2020. 
Com esse modo de fazer teatro, o grupo de atrizes e atores buscou romper "o cisma cultural que associa cada classe de obras a seu público” (BOURDIEU, 2007, p. 36), colocando em xeque os limites entre estética popular e estética erudita, apontados por Pierre Bourdieu, e se contrapondo no campo das artes cênicas à "hostilidade das classes populares e das frações menos ricas em capital cultural das classes médias em relação a qualquer espécie de experimentação formal” (BORDIEU, 2007, p. 35), seja no teatro, na pintura, na fotografia ou no cinema.

Paradoxalmente, ao eleger a distância como personagem oculto do espetáculo teatral, a peça se aproxima do habitus e do cotidiano das classes populares (e da vida real), como defende seu diretor. "Mal invisível”, ao problematizar artisticamente a distância e o isolamento, também se antecipou premonitoriamente à eclosão da pandemia no Brasil e no Mundo, nos meses que se seguiriam...

\section{REFERÊNCIAS BIBLIOGRÁFICAS}

BOURDIEU, P. A Distinção - crítica social do julgamento. Tradução de Daniela Kern e Guilherme J. F. Teixeira. São Paulo: EDUSP; Porto Alegre: Zouk, 2007.

HEIDEGGER, M. Ser e tempo. Tradução revisada de Marcia Sá Cavalcante Schuback. 6. ed. Petrópolis: Editora Vozes; Bragança Paulista: Editora Universitária São Francisco, 2012.

LÉVY, J.; LUSSAULT, M. Dictionaire de la Géographie et de l'Espace des Societés. Paris: Belin, 2003.

MERLEAU-PONTY, M. Fenomenologia da percep̧ão. Tradução de Carlos Alberto Ribeiro de Moura. 3. ed. São Paulo: Martins Fontes, 2006.

OXFAM Brasil. A distância que nos une - Um retrato das desigualdades brasileiras. Relatório de pesquisa, setembro de 2017.

SAYURI, J. Coronavírus: qual o impacto do isolamento nas sociedades mais 'abertas' do mundo. BBC News Brasil, 28 março 2020.2 Disponível em: https://www.bbc.com/portuguese/internacional-52042839. Acesso em: 26/11/2020.

SERPA, A. O Espaço Público na Cidade Contemporânea. São Paulo: Editora Contexto, 2007.

SERPA, A. Diversidade e desigualdade em um contexto de fragmentação socioespacial: avanços e recuos. Atelie geográfico (UFG), v. 12, p. 22-38, 2018.

THOMSON, R. et al. Relational mobility predicts social behaviors in 39 countries and is tied to historical farming and threat. PNAS - Proceedings of the National Academy of Sciences of the United States of America, v. 115, n. 29, p. 7521-7526, July 17, 2018; first published June 29, 2018; https://doi.org/10.1073/pnas.1713191115. Disponível em: https://www.pnas.org/content/115/29/7521. Acesso em: 26/11/2020 